\title{
Prevalence and Correlates of Physical Assault on Dating Partners
}

\author{
Ko Ling Chan ${ }^{*}, 1$ and Murray A. Straus ${ }^{2}$ \\ ${ }^{1}$ Department of Social Work and Social Administration, The University of Hong Kong, Hong Kong \\ ${ }^{2}$ Family Research Laboratory, University of New Hampshire, Durham, NH, USA
}

\begin{abstract}
This paper examines the prevalence and correlates of dating partner violence in a cohort of 1,736 university students from Hong Kong and the United States. The participants completed the Revised Conflict Tactics Scale and the Personal and Relationships Profile to report on the rates of occurrence of physical assault and injury. The differences between the two sites were compared using independent t-tests. Logistic regression was employed to predict the presence or absence of physical assault in the previous year of reporting based on the demographic variables. Results showed that more Hong Kong students reported physical assault than did US students. A combination of the perpetrator-related demographic characteristics, and relationship and personal factors accounted for the differences in the preceding-year prevalence of physical assault perpetration in the two samples. To further investigate dating violence in diverse social settings, cultural factors correlated to dating violence should be taken into consideration.
\end{abstract}

\section{INTRODUCTION}

\section{Physical Assault on Dating Partners}

Though dating violence is a social phenomenon, it is one that is largely "hidden" and so is in need of further investigation [1]. The prevalence of dating violence ranges from $9 \%$ [2], to $65 \%$ [3] when verbal aggression is taken into account. It has been estimated that about one-third of high school and college students have experienced dating violence [4-10]. Many scholars have suggested that mild forms of abuse such as shoving, pushing, and so on, are more common in dating relationships than severe forms such as beating or attacking with weapons [11]. In Canada, about $35 \%$ of women have reported being physically abused [12]; some estimates put the figure as high as $45 \%$ [13]. The samples investigated in the existing studies of dating violence were predominantly from White, heterosexual, and college populations. Moreover, the literature is primarily American, with a few Canadian and British studies [14]. There is therefore a need for studies of different ethnicities, especially non-White groups. Much of the dating violence research excludes ethnic minorities due to small sample sizes [4]. This paper investigates the ways in which the prevalence of dating partner violence is similar and dissimilar in Western and Eastern societies. It presents findings for Hong Kong and for the United States on the rates of occurrence of physical assault and injury among university students.

Although few studies of dating violence have been conducted in Hong Kong or other Asian societies, it is hardly surprising that one can find violence in dating relationships in Hong Kong given its patriarchal social structure and associated beliefs. However, Makepeace [15] reported that

\footnotetext{
*Address correspondence to this author at the Department of Social Work and Social Administration, The University of Hong Kong, Hong Kong; E-mail: eklchan@hkucc.hku.hk
}

Asians have the lowest dating violence rate of $4.8 \%$ when compared to other races (e.g. Native Americans, Arabs, etc.). In a study of battered women, about $6.6 \%$ of the participants had experienced violence from their partner during courtship [16].

There is no exact definition of dating violence as different researchers have different perceptions of it, often dependent on their focus of research. For instance, some definitions consider verbal aggression as one form of dating violence while others do not $[13,17]$. Generally speaking, dating violence includes threatening communication, verbal abuse, and physical aggression [18]. The definition of Sugarman and Hotaling [4] has been widely adopted in the literature on dating violence due to its simplicity and specificity $[10,18,19]$. For the purpose of this study, dating is defined as a dyadic relationship involving social interaction and joint activities with an explicit or implicit intention to continue the relationship [20]. Despite the different social norms for dating in different societies, there are some inherent structural similarities; for example, it is a dyadic relationship, and social interactional processes typical of dyads are likely to apply.

\section{GENDER DIFFERENCES}

It is generally accepted that men inflict more violence on women whereas women experience more victimization. This might be because men are stereotyped as being more powerful when compared with the opposite sex. These views have gained some empirical support [21-24]. However, some data have been compiled that contradict this. Ryan [25] reported that men experience higher rates of victimization and women inflict more physical aggression on their partners. Some researchers have found no marked gender difference in the frequency of violence [26, 27] and that courtship violence was usually mutual [4, 28, 29]. In the debate over the equivalence of gender violence, some researchers investigated the motivation and effect of violence. Women are less likely to think force is justifiable 
[30], which may mean they report violence more frequently. Violent acts initiated by males are generally more devastating and result in greater injuries to the victim [31]. Three times more women than men have reported severe emotional trauma as a result of dating violence [22]. This is likely due to women's experiencing more severe violence and sustaining greater injuries than men. In a study of dating violence literature, Lewis [18] found that $50 \%$ of women, versus $18 \%$ of men, reported serious injuries as a result of courtship battering.

\section{ABOUT THE STUDY}

This article uses the data samples for Hong Kong and the US in the International Dating Violence study to compare and contrast the prevalence and risk factors of dating partner violence. The International Dating Violence study was conducted by members of a research consortium, and Hong Kong was one of the sites of the study. One of the strengths of the study is that it applied well-validated instruments such as the revised Conflict Tactics Scales (CTS2) [32] to measure intimate partner violence and the Personal and Relationships Profile (PRP) [33] to measure a wide range of etiological variables associated with partner violence.

\section{MATERIALS AND METHODOLOGY}

\section{Sample and Sampling Procedures}

The participants of this study were 2,161 university students from Hong Kong, China and New Hampshire, USA, representing a response rate of over $90 \%$. The sample for the purposes of analysis included 1,736 participants because not all the students were in or had recently been in a dating relationship. As with other surveys, not everyone answered every question. Indeed, to respect the privacy and the voluntary nature of participation, the instructions emphasized that the participants were free to ignore any question they did not wish to answer. The data were obtained by administering questionnaires to students in introductory sociology and psychology classes at the University of New Hampshire, and students in social work and other social science classes at the University of Hong Kong. The procedures were approved by the ethics committees of the University of Hong Kong and the University of New Hampshire.

Table 1 shows the demographic information of the participants in the Hong Kong and US samples. About $70 \%$ of the participants were female. For most of the characteristics listed in Table $\mathbf{1}$, there were significant differences between the Hong Kong and US samples. Generally speaking, the US student sample was younger than the Hong Kong sample. Parents' education level for the US sample was higher. The socioeconomic status (SES) scale was created by summing the scores for the education of the participants' father and mother (each with a possible score of 1-6) and family income (with a possible score of 1-8). The range of the scale was 3 to 20. The alpha coefficient of reliability for the SES scale was 0.71 . The mean scores for the Hong Kong and US samples were 8.26 and 14.05 respectively. Although the family incomes of the Hong Kong and US samples were not comparable because different ranges of income were used in the responses, a comparison can still be made based on the proportion of participants who reported a high SES.

The divorce rate of the US students' parents was $21.9 \%$, which was significantly higher than the rate of $6.3 \%$ for the Hong Kong students' parents. Regarding the nature of the dating relationship, more Hong Kong students than US students were engaged in a current relationship, and their relationships had lasted longer. A very high proportion of Hong Kong participants $(70.3 \%)$ were living with their parents.

\section{Measures}

The questionnaire had three main components: an introductory section with demographic questions, the CTS2 to provide the data on the four aspects of partner violence, and the Personal and Relationships Profile to provide data on 21 aspects of etiology. The questionnaire could be completed within one class period. This paper discusses only the results from the CTS2 and the associative demographic factors.

\section{Dependent Variable}

Physical assault perpetrated by the participants against a current or former partner within the year prior to the interview was defined as the dependent variable. This measure of physical assault was derived from the CTS2(32), which is an instrument designed to reveal the percentage of a sample (prevalence) who have been assaulted in a dating relationship and the frequency of such acts (chronicity). With conflict theory as its theoretical basis, the CTS2 was designed to measure the extent to which specific tactics, including physical assault, injury, sexual coercion, and psychological aggression, have been used in intimate relationships. The items of the scales report on actual behavioral acts of violence. The subjects were asked to respond to items that measure physical assault. These included items for minor assault, such as "threw something at my partner that could hurt", "twisted my partner's arm or hair", "pushed or shoved my partner", "grabbed my partner", and "slapped my partner". Items also measured severe assault, such as "used a knife or gun on my partner", "punched or hit my partner with something that could hurt", "choked my partner", "slammed my partner against a wall", "beat up my partner", "burned or scalded my partner on purpose", and "kicked my partner".

The internal consistency reliability of the CTS2 scales is generally high, with an alpha coefficient ranging from .79 to $.95(32)$, and it has high cross-cultural reliability [34]. In terms of criterion validity, an increasing severity of tactics has been shown to correlate with increasing injury severity [35]. The CTS2 has been translated into Chinese with satisfactory levels of reliability and validity [36]. In this study, the CTS2 showed satisfactory reliability ( $\alpha$ ranged from .70 to .91 ). The analyses in this paper used data from the physical assault and injury scales. The following scores were computed:

\section{Preceding-year Prevalence}

This refers to the percentage of participants who had been physically aggressive toward their partner over the preceding year. 
Table 1. Characteristics of Participants

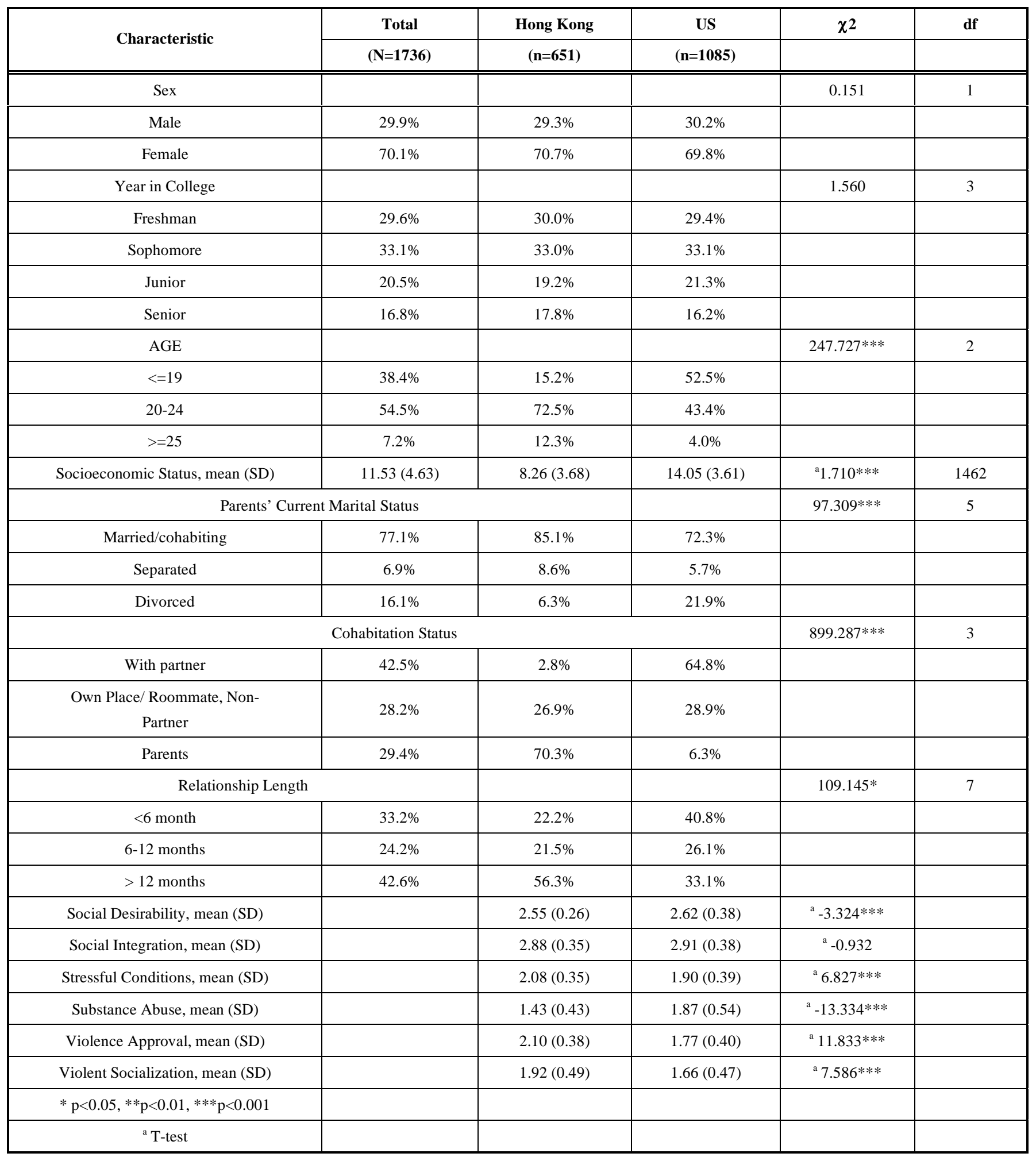

\section{Chronicity}

This represents the number of incidents of physical assault over the preceding year. In this study, chronicity was only calculated for participants who had carried out at least one incident of physical assault on their partners during the preceding year.

\section{Severity}

The CTS2 includes subscales for two levels of severity. The Minor Assault scale includes acts such as slapping or throwing something at the partner. The Severe Assault scale includes acts such as punching and choking. 


\section{Severity Level}

A problem with the Minor Assault scale is that some of the participants who reported minor assaults probably also carried out more severe attacks on their partner. In order to have a variable for which the two are mutually exclusive, the participants were classified into one of three categories: $1=$ None; 2 = Minor Only, that is, one or more acts of minor violence and no instance of severe violence; and $3=$ Severe. The Severity Level variable was also used as an ordinal measure of the severity of violence.

\section{Independent Variables}

Perpetrator-related demographic characteristics include sex, year in college, age, and socioeconomic status. The Socioeconomic status (SES) scale was created to measure socioeconomic status by computing the number of years of education completed by the student's father and mother, and family income [20]. The mean scores on the SES scale for the Hong Kong and US samples were $8.3(S D=3.7)$ and $14.1(S D=3.6)$ respectively. The alpha coefficients of reliability for the SES scales for the Hong Kong and US samples were 0.71 and 0.67 respectively.

Relationship factors include parents' current marital status, cohabitation status, and relationship length. Personal factors include factors measured by the Personal and Relationships Profile (PRP), which is a multi-scale instrument that provides a profile of scores for 22 variables that have been found to have an empirical relationship with violence against a dating partner [33]. The validity and reliability of the PRP is satisfactory [37]. The instrument was translated into Chinese and back translated to check for any interpretation discrepancies. The final Chinese version was further examined by two clinical psychologists and three experienced social workers in the field of domestic violence to ensure its practical value.

In this paper, analyses were performed on six PRP factors. Social desirability was the degree to which a respondent will tend to avoid admitting undesirable behavior, such as partner assault and other forms of crime. Social integration indicated an individual's attachment to society and social norms. Stressful conditions are the stress or hassles experienced in daily living. Substance abuse referred to excessive use of alcohol or other mind-altering drugs that manifest significant adverse consequences. Violence approval was assessed by the extent to which use of physical force is acceptable in a variety of interpersonal situations.
Violent socialization was measured by the extent to which a respondent experienced, witnessed, and received violencesupporting attitudes and behaviors during childhood. In this study, the reliability alpha of the selected factors ranged from 0.6 to 0.8 (see Table 2). The mean alpha coefficient of the whole sample, the Hong Kong sample, and the US sample was 0.7 , which demonstrated satisfactory reliability of the Chinese and English versions of the six factors of the PRP.

\section{Data Collection}

The data were gathered using procedures reviewed by and approved by the boards for protection of human subjects at each of these universities. The purpose of the study and the students' right to not participate were explained orally as well as in printed form at the beginning of each session. The participants were told that the questionnaire asked about their attitudes, beliefs, and experiences they may have had, and that the questionnaire included questions on sensitive issues, including sexual relationships. They were assured of anonymity and confidentiality. A debriefing form was given to each participant as they left. The form explained the study in more detail and provided names and telephone numbers of mental health services and community resources such as services for battered women.

\section{Data Analysis}

Analysis included the prevalence and chronicity of dating partner violence, and demographic variables for the presence and absence of violence. The $t$-test was used to assess whether the means of the Hong Kong and US samples were statistically different from each other. Logistic regression was used to predict the presence or absence of physical assault in the preceding year of reporting based on the demographic and PRP variables. Logistic regression is an appropriate technique when the dependent variable is dichotomous. Odds ratios have been previously used in the study of physical assault [38]. The interpretation of odds ratios is simple. An odds ratio greater than 1.00 indicates that the independent variable is associated with an increase in the odds of the dependent variable. An odds ratio below 1.00 indicates that the independent variable is associated with a decrease in the odds of the dependent variable. The Hosmer and Lemeshow test was used to assess the goodness of fit of the logistic regression analysis. A non-significant result implies adequacy of the logistic model.

Table 2. Alpha Coefficients of Reliability for PRP

\begin{tabular}{|c|c|c|c|c|}
\hline Measure & Items & Total & HK & 0.69 \\
\hline \hline Social Desirability & 13 & 0.73 & 0.57 & 0.75 \\
\hline Social Integration & 10 & 0.56 & 0.64 & 0.63 \\
\hline Stressful Conditions & 9 & 0.68 & 0.83 & 0.70 \\
\hline Substance Abuse & 8 & 0.80 & 0.78 \\
\hline Violence Approval & 10 & 0.75 & 0.77 \\
\hline Violent Socialization & 8 & & 0.74 \\
\hline
\end{tabular}


Table 3. Preceding-year Prevalence and Chronicity of Dating Partner Violence in Hong Kong (HK) and United States (US)

\begin{tabular}{|c|c|c|c|c|c|c|c|c|c|c|c|}
\hline \multirow[b]{2}{*}{ Measure } & \multicolumn{4}{|c|}{ HK } & \multicolumn{4}{|c|}{ US } & \multirow{2}{*}{$\begin{array}{c}\text { p-value } \\
\text { (HK-US } \\
\text { Overall) }\end{array}$} & \multirow{2}{*}{$\begin{array}{c}\text { p-value } \\
\text { (HK-US } \\
\text { Male) }\end{array}$} & \multirow{2}{*}{$\begin{array}{l}\text { p-value } \\
\text { (HK-US } \\
\text { Female) }\end{array}$} \\
\hline & $\begin{array}{c}\text { Total } \\
(\%)\end{array}$ & $\begin{array}{c}\text { Male } \\
(\%)\end{array}$ & $\underset{(\%)}{\text { Female }}$ & $\begin{array}{c}\text { p-value } \\
\text { (HK: M-F) }\end{array}$ & $\begin{array}{c}\text { Total } \\
(\%)\end{array}$ & $\begin{array}{c}\text { Male } \\
(\%)\end{array}$ & $\begin{array}{c}\text { Female } \\
(\%)\end{array}$ & $\begin{array}{c}\text { p-value } \\
\text { (US: M-F) }\end{array}$ & & & \\
\hline \multicolumn{12}{|l|}{ PHYSICAL ASSAULT } \\
\hline \multicolumn{12}{|l|}{ Overall } \\
\hline Prevalence & 46.08 & 36.20 & 49.30 & $0.01 *$ & 29.50 & 28.50 & 29.90 & 0.64 & $0.00^{*}$ & 0.12 & $0.00^{*}$ \\
\hline Chronicity - Mean & 17.22 & 21.20 & 16.25 & 0.38 & 9.64 & 14.50 & 7.58 & $0.01 *$ & $0.00 *$ & 0.20 & $0.00 *$ \\
\hline$-\mathrm{SD}$ & 25.14 & 36.31 & 21.60 & & 15.76 & 24.15 & 9.99 & & & & \\
\hline \multicolumn{12}{|l|}{ Severe Level } \\
\hline Prevalence & 21.71 & 13.50 & 24.30 & $0.01^{*}$ & 9.60 & 8.50 & 10.10 & 0.42 & $0.00^{*}$ & 0.17 & $0.00 *$ \\
\hline Chronicity - Mean & 13.18 & 25.27 & 11.02 & 0.11 & 7.44 & 18.62 & 3.36 & $0.00 *$ & $0.01 *$ & 0.44 & $0.00 *$ \\
\hline$-\mathrm{SD}$ & 17.08 & 32.22 & 11.75 & & 13.52 & 22.24 & 4.09 & & & & \\
\hline \multicolumn{12}{|l|}{ INJURY TO PARTNER } \\
\hline \multicolumn{12}{|l|}{ Overall } \\
\hline Prevalence & 8.43 & 10.80 & 7.60 & 0.86 & 7.95 & 9.40 & 7.30 & 0.34 & 0.80 & 0.68 & 0.86 \\
\hline Chronicity - Mean & 12.16 & 26.00 & 5.52 & $0.04 *$ & 9.24 & 14.24 & 6.26 & $0.01 *$ & 0.33 & 0.22 & 0.73 \\
\hline$-\mathrm{SD}$ & 20.80 & 30.49 & 9.01 & & 11.63 & 14.31 & 8.76 & & & & \\
\hline \multicolumn{12}{|l|}{ Severe Level } \\
\hline Prevalence & 2.79 & 6.30 & 1.60 & 0.16 & 2.24 & 4.30 & 1.40 & $0.03 *$ & 0.60 & 0.39 & 0.82 \\
\hline Chronicity - Mean & 19.67 & 26.14 & 10.60 & 0.31 & 12.96 & 18.15 & 6.10 & $0.01 *$ & 0.39 & 0.52 & 0.44 \\
\hline$-\mathrm{SD}$ & 25.20 & 30.03 & 14.76 & & 11.27 & 11.43 & 7.67 & & & & \\
\hline
\end{tabular}

$* \mathrm{P}<0.05$

\section{RESULTS}

\section{Prevalence and Chronicity of Dating Partner Violence}

Table 3 shows that about $46 \%$ of the participants from the Hong Kong sample reported an act of physical assault against a dating partner in the preceding year. This was significantly higher than the figure of $30 \%$ for the US sample. The same difference can be found in the chronicity and the severe level of physical assault. The prevalence rates of the Hong Kong and US samples are consistent with other studies of violence by university students against a dating partner [4, 39]. There were no significant differences in the prevalence of physical assault on a partner as reported by the Hong Kong and US males. However, Hong Kong females showed a significantly higher prevalence rate of physically assaulting a partner than did the US females. This difference in the prevalence of physical assault cannot be generalized by concluding that Hong Kong students are more violent than their US counterparts because the samples obtained were not representative of university students or of the societies as a whole.

A rate of about $8 \%$ for injury inflicted against a dating partner was found for the Hong Kong and US students in the preceding year. For the chronicity of overall and severe levels of injury caused to a partner, the Hong Kong male and female participants showed slightly higher rates than their US counterparts, though this was not significant.

\section{Gender Differences in Perpetrating Violence}

The discussion of gender differences in dating partner violence has focused on whether men or women are more violent [14]. The preceding-year prevalence of violence is used as an indicator to show the gender difference [4]. Table 3 shows the gender differences in perpetrating violence in both sites. The Hong Kong female participants used significantly more physical violence than did the male participants. The same pattern existed for the severe level of physical assault. However, for chronicity, the frequency of male-inflicted physical violence was higher than that of female-inflicted violence. The US data showed a significant level of difference. Again, the injury caused by male participants was generally worse than that caused by female participants. The data from the Hong Kong students showed a significant difference in the chronicity of injury, while the US data indicated significantly higher chronicity at the overall and severe levels of injury and a higher prevalence rate at the severe level.

Table 4 shows a general pattern of gender violence in terms of severity level. Generally speaking, more US and Hong Kong female participants perpetrated physical assault against their dating partners than did the male participants. However, when examining the injury level, the picture has to be re-interpreted. There was a general tendency that the injury caused by the male participants against their dating 
Table 4. Severity and Types of Dating Partner Violence by Gender in the Hong Kong and US Samples

\begin{tabular}{|c|c|c|c|c|}
\hline \multirow{2}{*}{ Measure } & \multicolumn{2}{|c|}{ HK } & \multicolumn{2}{|c|}{ US } \\
\hline & $\begin{array}{c}\text { Minor Only } \\
(\%)\end{array}$ & $\begin{array}{c}\text { Severe } \\
(\%)\end{array}$ & $\begin{array}{c}\text { Minor Only } \\
(\%)\end{array}$ & $\begin{array}{c}\text { Severe } \\
(\%)\end{array}$ \\
\hline \multicolumn{5}{|l|}{$\underline{\text { ASSAULT }}$} \\
\hline Preceding-year Prevalence of Physical Assault by Female & 18.70 & 23.26 & 20.10 & 10.68 \\
\hline Preceding-year Prevalence of Physical Assault by Male & 14.54 & 16.33 & 19.34 & 7.68 \\
\hline \multicolumn{5}{|l|}{$\underline{\text { INJURY }}$} \\
\hline Preceding-year Prevalence of Injury to Female & 4.42 & 3.26 & 6.03 & 2.33 \\
\hline Preceding-year Prevalence of Injury to Male & 3.96 & 2.56 & 5.74 & 2.24 \\
\hline
\end{tabular}

partners was more severe than that caused by the female participants.

\section{Logistic Regression}

Table $\mathbf{5}$ presents the results of the univariate and multiple logistic regressions on the preceding-year prevalence of physical assault perpetration. The results showed that, controlling for all other variables in the model, years in college - freshman $(\mathrm{aOR}=4.370 ; 95 \% \mathrm{CI}=1.081,17.667)$ and relationship length $-6-12$ months $(\mathrm{aOR}=2.968 ; 95 \% \mathrm{CI}$ $=1.091,8.075)$ significantly elevated the odds of physical assault in the Hong Kong sample.

In the US sample, relationship length - less than 6 months was associated with a $72 \%$ decrease in the odds of physical assault $(\mathrm{aOR}=0.277 ; 95 \% \mathrm{CI}=0.148,0.517)$ and violence approval was associated with $413 \%$ greater odds of physical assault $(\mathrm{aOR}=5.128 ; 95 \% \mathrm{CI}=2.253,11.671)$, after controlling for all other variables in the model. An odds ratio of $413 \%$ indicates that participants who have an attitude of violence approval would be 3.13 times more likely than those who do not to perpetrate physical assault against their partners in the preceding year of the study. In the Hong Kong and US samples, the Nagelkerke R square suggested that the models explained $26.5 \%$ and $17.7 \%$ of the variance in physical assault perpetration respectively, while the results of the Hosmer-Lemeshow (H-L) test were 0.285 and 0.467 respectively, which showed that the models were adequate.

\section{Logistic Regressions for the Hong Kong and US Samples Combined}

Table 6 provides the results of the sequential logistic regressions. The first model in Table $\mathbf{6}$ contains the results of the district variable without any controls. The Hong Kong sample had an odds ratio of $103 \%$ higher in physical assault perpetration in the preceding year compared to the US sample. The second model in Table 6 controlled for the perpetrator-related demographic characteristics, including sex, year in college, age, and socioeconomic status. Controlling for the perpetrator-related demographic characteristics did not decrease the difference in odds between the two samples. Similarly, when controlling for the relationship factors, including parents' current marital status, cohabitation status, and relationship length, in the third model the difference in odds was not decreased. The fourth model in Table $\mathbf{6}$ controlled for the personal factors, including social desirability, social integration, stressful conditions, substance abuse, violence approval, and violent socialization. The final model in Table 6 simultaneously controlled for all of the variables. With all variables controlled, the difference in the odds of physical assault perpetration in the preceding year became insignificant. In short, all the characteristics accounted for the Hong Kong sample's significantly higher odds of physical assault perpetration relative to the US sample. The Nagelkerke R square suggested that the model explained $24.5 \%$ of the variance in physical assault perpetration, while the result of the Hosmer-Lemeshow (H-L) test was 0.083, which showed that the model was adequate.

\section{DISCUSSION}

Whether men or women are more violent in dating relationships is a controversial issue. Studies of students at American universities have found that a larger percentage of women than men assault a dating partner [4]. The rates of perpetrating an assault resulting in an injury, as well as being a victim of an assault that resulted in an injury, were overwhelmingly higher for males. In this study, more US and Hong Kong female participants perpetrated physical assault against their dating partners than did male participants. However, there was a general tendency that the injury caused by the male participants against their dating partners was more severe than that caused by the female participants. The findings in this study are consistent with a meta-analysis of sex differences in physical aggression [40], which found that act-based measures, such as the Conflict Tactics Scales (CTS), and meaning-based measures showed conflicting results with respect to sex differences in physical aggression toward partners [40]. When measures were based on acts, women were significantly more likely than men to have used physical aggression toward their partners. However, when measures were based on the physical consequences of aggression, men were more likely than women to have injured their partners. In addition to measurement issues, Johnson [41] has argued that disparate results with respect to sex differences in violence can occur depending upon the sample studied. In community samples, women tend to perpetrate as much violence as or more violence than men. 
Table 5. Logistic Regression of Preceding-year Prevalence of Physical Assault Perpetration

\begin{tabular}{|c|c|c|c|c|}
\hline \multirow[b]{2}{*}{ Variable } & \multicolumn{2}{|c|}{ Hong Kong } & \multicolumn{2}{|c|}{ United States } \\
\hline & $\begin{array}{c}\text { Crude OR } \\
\text { (95.0\% CI for OR) }\end{array}$ & $\begin{array}{c}\text { Adjusted OR } \\
\text { (95.0\% CI for OR) }\end{array}$ & $\begin{array}{c}\text { Crude OR } \\
\text { (95.0\% CI for OR) }\end{array}$ & $\begin{array}{c}\text { Adjusted OR } \\
\text { (95.0\% CI for OR) }\end{array}$ \\
\hline \multicolumn{5}{|l|}{ Sex } \\
\hline Male & $0.583(0.385,0.882)^{* *}$ & $0.719(0.307,1.685)$ & $0.932(0.695,1.250)$ & $0.729(0.398,1.334)$ \\
\hline Female & 1.000 & 1.000 & 1.000 & 1.000 \\
\hline \multicolumn{5}{|l|}{ Year in College } \\
\hline Freshman & $2.282(1.345,3.870)^{* *}$ & $4.370(1.081,17.667)^{*}$ & $0.953(0.631,1.439)$ & $1.128(0.364,3.495)$ \\
\hline Sophomore & $1.280(0.763,2.148)$ & $1.424(0.431,4.703)$ & $1.126(0.756,1.678)$ & $1.029(0.414,2.559)$ \\
\hline Junior & $2.217(1.247,3.941)^{* *}$ & $3.270(0.910,11.750)$ & $0.836(0.535,1.307)$ & $0.774(0.344,1.741)$ \\
\hline Senior & 1.000 & 1.000 & 1.000 & 1.000 \\
\hline \multicolumn{5}{|l|}{ Age in Years } \\
\hline$<=19$ & $3.220(1.537,6.744)^{* *}$ & $2.026(0.342,11.986)$ & $2.256(0.980,5.192)$ & $1.351(0.277,6.604)$ \\
\hline $20-24$ & $2.766(1.461,5.237)^{* *}$ & $2.265(0.583,8.805)$ & $1.955(0.845,4.526)$ & $1.393(0.355,5.467)$ \\
\hline$>=25$ & 1.000 & 1.000 & 1.000 & 1.000 \\
\hline Socioeconomic Status & $1.007(0.960,1.057)$ & $1.078(0.952,1.220)$ & $0.958(0.918,1.000)^{*}$ & $0.950(0.881,1.023)$ \\
\hline \multicolumn{5}{|l|}{ Parents' Current Marital Status } \\
\hline Married/cohabiting & 1.000 & 1.000 & 1.000 & 1.000 \\
\hline Separated & $0.726(0.396,1.330)$ & $0.842(0.242,2.928)$ & $0.748(0.403,1.389)$ & $0.504(0.157,1.614)$ \\
\hline Divorced & $1.214(0.609,2.419)$ & $0.681(0.173,2.675)$ & $1.205(0.875,1.659)$ & $0.937(0.527,1.668)$ \\
\hline \multicolumn{5}{|l|}{ Cohabitation Status } \\
\hline With Partner & $0.495(0.152,1.610)$ & $1.290(0.144,11.548)$ & $1.059(0.581,1.931)$ & $0.601(0.272,1.330)$ \\
\hline Own Place/ Roommate, Non-Partner & $1.103(0.729,1.671)$ & $0.557(0.238,1.300)$ & $1.161(0.618,2.182)$ & $0.911(0.432,1.919)$ \\
\hline Parents & 1.000 & 1.000 & 1.000 & 1.000 \\
\hline \multicolumn{5}{|l|}{ Relationship Length } \\
\hline$<6$ Month & $0.400(0.248,0.645)^{* * *}$ & $0.875(0.346,2.213)$ & $0.407(0.286,0.581)^{* * *}$ & $0.277(0.148,0.517)^{* * *}$ \\
\hline 6-12 Months & $0.826(0.526,1.295)$ & $2.968(1.091,8.075)^{*}$ & $0.705(0.488,1.019)$ & $0.718(0.401,1.285)$ \\
\hline$>12$ Months & 1.000 & 1.000 & 1.000 & 1.000 \\
\hline Social Desirability & $0.361(0.188,0.695)^{* *}$ & $0.535(0.109,2.634)$ & $0.332(0.228,0.483)^{* * *}$ & $0.794(0.355,1.777)$ \\
\hline Social Integration & $0.392(0.225,0.683)^{* * *}$ & $0.314(0.088,1.123)$ & $0.376(0.237,0.599)^{* * *}$ & $0.799(0.360,1.777)$ \\
\hline Stressful Conditions & $1.568(0.911,2.699)$ & $1.237(0.361,4.237)$ & $1.830(1.178,2.844)^{* *}$ & $0.868(0.367,2.054)$ \\
\hline Substance Abuse & $0.631(0.341,1.167)$ & $0.429(0.156,1.175)$ & $1.628(1.258,2.107)^{* * *}$ & $1.315(0.776,2.229)$ \\
\hline Violence Approval & $1.950(1.165,3.265)^{* *}$ & $2.396(0.684,8.395)$ & $2.842(1.806,4.470)^{* * *}$ & $5.128(2.253,11.671)^{* * *}$ \\
\hline \multirow[t]{6}{*}{ Violent Socialization } & $1.349(0.928,1.962)$ & $0.906(0.390,2.102)$ & $1.249(0.873,1.789)$ & $0.742(0.379,1.454)$ \\
\hline & Constant & 11.194 & & .291 \\
\hline & -2 Log likelihood & 196.383 & & 424.471 \\
\hline & $\chi^{2}$ & 37.571 & & 53.774 \\
\hline & Nagelkerke $\mathrm{R}^{2}$ & .265 & & .177 \\
\hline & Hosmer \& Lemeshow test & .285 & & .467 \\
\hline
\end{tabular}


Table 6. Results of Sequential Logistic Regressions on Preceding-year Prevalence of Physical Assault Perpetration

\begin{tabular}{|c|c|c|c|c|c|}
\hline Covariates & $\begin{array}{c}\text { Model } 1 \\
\text { District: HK/US } \\
\text { n = 1,547 } \\
\text { Odds Ratio } \\
(95.0 \% \text { CI for } \\
\text { OR) }\end{array}$ & $\begin{array}{c}\text { Model 2 } \\
\text { Perpetrator-Related } \\
\text { Demographic } \\
\text { Characteristics } \\
\text { n = 1,515 } \\
\text { Odds Ratio } \\
\text { (95.0\% CI for OR) }\end{array}$ & $\begin{array}{c}\text { Model } 3 \\
\text { Relationship } \\
\text { Factors } \\
\text { n = 1,353 } \\
\text { Odds Ratio } \\
\text { (95.0\% CI for } \\
\text { OR) }\end{array}$ & $\begin{array}{c}\text { Model } 4 \\
\text { Personal factors } \\
\text { n }=806 \\
\text { Odds Ratio } \\
\text { (95.0\% CI for } \\
\text { OR) }\end{array}$ & $\begin{array}{c}\text { Model 5 } \\
\text { Full model } \\
\mathbf{n}=\mathbf{5 9 0} \\
\text { Odds Ratio } \\
\text { (95.0\% C } \\
\text { I for OR) }\end{array}$ \\
\hline HK & $\begin{array}{c}2.032 \\
(1.632,2.530)^{* * *}\end{array}$ & $\begin{array}{c}1.995 \\
(1.434,2.776)^{* * *}\end{array}$ & $\begin{array}{c}1.911 \\
(1.343,2.718)^{* * *}\end{array}$ & $\begin{array}{c}2.684 \\
(1.760,4.093)^{* * *}\end{array}$ & $\begin{array}{c}2.040 \\
(0.977,4.262)\end{array}$ \\
\hline US & 1.000 & 1.000 & 1.000 & 1.000 & 1.000 \\
\hline $\begin{array}{l}\text { Perpetrator-Related Demographic } \\
\text { Characteristics (Sex, Year in College, } \\
\text { Age, Socioeconomic Status) }\end{array}$ & & BLOCK & & & BLOCK \\
\hline $\begin{array}{l}\text { Personal Factors } \\
\text { (Social Desirability, Social Integration, } \\
\text { Stressful Conditions, Substance Abuse, } \\
\text { Violence Approval, } \\
\text { Violent Socialization) }\end{array}$ & & & & BLOCK & BLOCK \\
\hline Constant & 0.421 & 0.242 & 0.556 & 8.237 & 0.630 \\
\hline -2 Log likelihood & 1963.777 & 1585.120 & 1643.097 & 955.171 & 646.865 \\
\hline$\chi^{2}$ & $40.103^{* * *}$ & $53.765^{* * *}$ & $86.158^{* * * *}$ & $99.101 * * *$ & $115.248 * * *$ \\
\hline Nagelkerke $\mathrm{R}^{2}$ & 0.035 & .057 & 0.086 & 0.159 & .245 \\
\hline
\end{tabular}

$* \mathrm{P}<0.05, * * \mathrm{P}<0.01, * * * \mathrm{P}<0.001$

Note: $\mathrm{OR}=$ odds ratio $; \mathrm{CI}=$ confidence interval

Our findings underscore the need to obtain information on countries to compare the prevalence of dating partner violence as well as the associated risk factors. As previous studies have found, more Hong Kong students reported physical assault than did US students [20]. The results of this study suggest that a combination of the perpetrator-related demographic characteristics, relationship factors, and personal factors accounted for the differences in the preceding-year prevalence of physical assault perpetration between the Hong Kong and US samples. Hong Kong and the United States represent two different cultures. Hong Kong is itself a modern city exposed to the influence of Western culture while at the same time it has inherited much traditional Chinese culture [42]. In this study, the samples obtained from these two sites demonstrated significant differences in demographic factors that might contribute to the difference in the prevalence of dating violence.

The two samples had significant differences in the risk factors. The effect of age on the prevalence of physical violence is consistent with a study which found that the prevalence of intimate violence was higher for the younger students [43]. SES has an influence on the prevalence of physical violence. Hong Kong students' parents are not likely to have received higher education since in the 1970s and '80s when their parents were of school age, there were few opportunities to receive it. Those who did obtain a university degree could expect a far better living standard and thus a higher SES. Beginning in the '90s, students have had more opportunity to enter university. When compared to US students, more Hong Kong students today are in relationships which are longer in relationship length. Relationship length is a consistent and powerful predictor of physical assault. It has been found that the length of a relationship, mediated by the level of emotional commitment, was a crucial factor in triggering courtship violence [44, 45].

The Hong Kong and US students were under different modes of parenting control and enjoyed different levels of freedom. The divorce rate of the US students' parents was found to be significantly higher than that of the Hong Kong students' parents. This indicates that the stability of family and parental care The Hong Kong and US students were under different modes of parenting control and enjoyed different levels of freedom. The divorce rate of the US students' parents was found to be significantly higher than that of the Hong Kong students' parents. The Hong Kong students were more likely to be living with their parents who would therefore exert more control over their children. Only $2.8 \%$ of the Hong Kong students were cohabiting with their partner whereas the figure was as high as $64.8 \%$ for the US students. The Hong Kong students were generally from 
families with stronger parental influence and thus stronger family socialization than US students. Cultural norms can have an effect on attitudes toward using violence [46]. Hong Kong society is still more tolerant of violence in intimate relationships since, according to traditional Chinese culture, violence that does not lead to injury is regarded as an expression of love and care toward a partner.

The study has certain limitations. The incidents of selfreported partner violence are likely to be underreported. In Archer's [40] study, self-reports of using physical aggression were found to be lower than partner reports. The comparisons made between the Hong Kong and US samples are based on the results of the CTS2. This measure may have limited cross-cultural comparability, though it has been demonstrated to have excellent cross-cultural reliability. Except for a small number of studies [12, 47, 48] that used representative samples in national surveys, most studies utilized college and university student samples. The key problem with a research literature that relies so heavily on these samples is its representation [14, 18]. These studies cannot make generalizations about nations or even about university students in the nations where the data were gathered. College and university samples also tend to represent middle- to upper-class socioeconomic groups [14].

However, university students are an important population for examining dating violence for at least three reasons. First, as indicated above, a large number of studies show that physical assaults occur very frequently among student dating couples. The rate of physical assault typically ranges from $25 \%$ to $40 \%$ [4]. College students are also an appropriate group to examine because they constitute a sizeable population. In the United States, for example, there are about 15 million students currently enrolled in higher education institutions, while in Hong Kong, there are about 0.1 million. Finally, college students are at a formative period in their lives, especially in regard to the development of appropriate patterns of behavior with intimate partners. The patterns manifested at this age are often enduring features of their relationships.

Although there are differences in the prevalence rate of dating partner violence between the United States and Hong Kong, the rates are still high at both sites. Violence in intimate relationships starts as early as the stage of courtship. Efforts to prevent dating partner violence should start when individuals are still of school age, and there should be an emphasis on stopping even a minor level of physical assault.

An accurate comparison of dating partner violence at two different sites may be limited by the variation in the methods of data collection and sampling. The SES of the samples differed significantly. Family socialization and thus the inheritance of culture would therefore be different. To further investigate dating violence in diverse social settings, cultural factors correlated to dating violence should be taken into consideration. One example is the cultural difference in the meaning of violence in intimate relationships. Gender role expectations in courtship lead to different definitions of the meaning of violence, while justification of violence as an expression of love increases the tolerance of violence and public acceptance of violence in intimate relationships reduces victims' likelihood of seeking help from others.
A comparison of cultures is always difficult. The Chinese are a diversified people spread across many different societies. The Chinese population is made up of immigrants in Western societies, and those living in Chinese societies like Mainland China, Hong Kong, Macau, and Taiwan. These Chinese societies differ in terms of their sociopolitical-economic structures. Likewise, the United States is composed of different ethnic groups with different cultures. One important question concerns whether the factors studied are real factors explaining the differences between the US and Hong Kong samples. Any interpretation of culturespecific risk factors should be undertaken with caution because a culture affects people growing up and living in that culture, but in different ways according to the sociopolitical-economic characteristics of the society.

\section{CONCLUSION}

This paper has documented findings from the two sites of the research consortium of the International Dating Violence Study. A further analysis of these risk factors would contribute to the study of how the etiology of partner violence is similar and dissimilar in Western and Eastern societies.

\section{REFERENCES}

[1] Ferguson CU. Dating violence as a social phenomenon. In: Jackson NA, Oates GC, Eds. Violence in intimate relationships: Examining sociological and psychological issues. Boston: ButterworthHeinemann 1998; pp. 83-118.

[2] Roscoe B, Callahan JE. Adolescents' self-report of violence in families and dating relations. Adolescence 1985; 20: 545-53.

[3] Laner MR. Courtship Abuse and Aggression: Contextual Aspects. Sociol Spectr 1983; 3: 69-83.

[4] Sugarman DB, Hotaling GT. Dating violence: Prevalence, context, and risk markers. In: Pirog-Good MA, Stets JE, Eds. Violence in dating relationships: Emerging social issues. New York, NY, England: Praeger Publishers 1989; pp. 3-32.

[5] Sugarman DB, Hotaling GT. Dating violence: a review of contextual and risk factors. In: Levy B, editor. Dating violence: Young Women in Danger. Seattle: Seal Press 1991; pp. 100-18.

[6] Lane KE, Gwartney Gibbs PA. Violence in the Context of Dating and Sex. J Fam Issues 1985; 6: 45-59.

[7] Arias I, Samios M, O'Leary KD. Prevalence and correlates of physical aggression during courtship. J Interpers Violence 1987; 2: 82-90.

[8] Marshall LL, Rose P. Premarital violence: the impact of family of origin violence, stress, and reciprocity. Violence Vict 1990; 5: 5164.

[9] Foshee VA. Gender differences in adolescent dating abuse prevalence, types and injuries. Health Educ Res 1996; 11: 275-86.

[10] O'Keefe M. Predictors of dating violence among high school students. J Interpers Violence 1997; 12: 546-68.

[11] Roscoe B, Benaske N. Courtship violence experienced by abused wives: Similarities in patterns of abuse. Fam Relat 1985; 34: 41924.

[12] DeKeseredy WS, Schwartz MD. Woman abuse on campus: Results from the Canadian national survey. Thousand Oaks: Sage Publications 1998.

[13] Pedersen P, Thomas CD. Prevalence and correlates of dating violence in a Canadian university sample. Can J Behav Sci 1992; 24: 490-501.

[14] Jackson SM. Issues in the dating violence research: A review of the literature. Aggress Violent Beh 1999; 4: 233-47.

[15] Makepeace JM. Social factor and victim-offender differences in courtship violence. Fam Relat 1987; 36: 87-91.

[16] Chan KL. Study of the impact of family violence on battered women and their children. Hong Kong: Christian Family Service Centre and Department of Social Work \& Social Administration, the University of Hong Kong (Resource Paper Series No. 38) 2000. 
[17] O'Keeffe NK, Brockopp K, Chew E. Teen dating violence. Soc Work 1986; 31: 465-8.

[18] Lewis SF, Fremouw W. Dating violence: A critical review of the literature. Clin Psychol Rev 2001; 21: 105-27.

[19] O'Keefe M. Factors mediating the link between witnessing interparental violence and dating violence. J Fam Violence 1998; 13: 39-57.

[20] Straus MA. Prevalence of violence against dating partners by male and female university students worldwide. Violence Against Women 2004; 10: 790-811.

[21] Makepeace JM. Life events stress and courtship violence. Fam Relat 1983; 32: 101-9.

[22] Makepeace JM. Gender differences in courtship violence victimization. Fam Relat 1986; 35: 383-8.

[23] Bethke TM, DeJoy DM. An experimental study of factors influencing the acceptability of dating violence. $\mathrm{J}$ Interpers Violence 1993; 8: 36-51.

[24] Bookwala J, Frieze IH, Smith C, Ryan K. Predictors of dating violence: A multivariate analysis. Violence Vict 1992; 7: 297-311.

[25] Ryan KM. The relationship between courtship violence and sexual aggression in college students. J Fam Violence 1998; 13: 377-94.

[26] Riggs DS, O'Leary KD. A theoretical model of courtship aggression. In: Pirog-Good MA, Stets JE, Eds. Violence in dating relationships: Emerging social issues. New York, NY, England: Praeger Publishers 1989; pp. 53-71.

[27] Molidor C, Tolman RM. Gender and contextual factors in adolescent dating violence. Violence Against Women 1998; 4: 18094.

[28] Gwartney Gibbs PA, Stockard J, Bohmer S. Learning courtship aggression: The influence of parents, peers, and personal experiences. Fam Relat 1987; 36: 276-82.

[29] Sigelman CK, Berry CJ, Wiles KA. Violence in college students' dating relationships. J Appl Soc Psychol 1984; 14: 530-48.

[30] Follingstad DR, Wright S, Lloyd S, Sebastian JA. Sex differences in motivations and effects in dating violence. Fam Relat 1991; 40: 51-7.

[31] Arias I, Johnson P. Evaluations of physical aggression among intimate dyads. J Interpers Violence 1989; 4: 298-307.

[32] Straus MA, Hamby SL, Boney-McCOY S, Sugarman DB. The Revised Conflict Tactics Scales (CTS2): Development and preliminary psychometric data. J Fam Issues 1996; 17: 283-316.

[33] Straus MA, Hamby SL, Boney-McCoy S, Sugarman DB. The Personal and Relationships Profile (PRP). Unpublished Manuscript. Durham, NH: Family Research Laboratory 1999.
[34] Straus MA. Cross-Cultural Reliability and Validity of the Revised Conflict Tactics Scales: A Study of University Student Dating Couples in 17 Nations. Cross-Cult Res 2004; 38: 407-32.

[35] Coben JH, Forjuoh SN, Gondolf EW. Injuries and health care use in women with partners in batterer intervention programs. J Fam Violence 1999; 14: 83-94.

[36] Chan KL. Correlates of wife assault in Hong Kong Chinese families. Violence Vict 2004; 19: 189-201.

[37] Straus MA, Mouradian VE, editors. Preliminary psychometric data for the personal and relationships profile (PRP): A multi-scale tool for clinical screening and research on partner violence. American Society of Criminology 1999; Toronto, Ontario.

[38] Straus MA, Ramirez IL, Eds. Criminal history and physical assault of college dating partners. American Society of Criminology annual meeting; 1999; Toronto, Ontario.

[39] Katz J, Kuffel SW, Coblentz A. Are there gender differences in sustaining dating violence?: An examination of frequency, severity, and relationship satisfaction. J Fam Violence 2002; 17: 247-71.

[40] Archer J. Sex differences in aggression between heterosexual partners: A meta-analytic review. Psychol Bull 2000; 126: 651-80.

[41] Johnson MP. Patriarchal Terrorism and common couple violence: Two forms of violence against women. J Marriage Fam 1995; 57: 283-94.

[42] Chow NWS. Western and Chinese ideas of social welfare. Int Soc Work 1987; 30: 31-41.

[43] Straus MA, Gelles RJ, Steinmetz SK. Behind closed doors: Violence in the American family. Garden City, NY: Anchor; 1980.

[44] Laner MR, Thompson J. Abuse and Aggression in Courting Couples. Deviant Behav 1982; 3: 229-44.

[45] Billingham RE. Courtship violence: The patterns of conflict resolution strategies across seven levels of emotional commitment. Fam Relat 1987; 36: 283-9.

[46] Stets JE, Straus MA. The marriage license as a hitting license: A comparison of assaults in dating, cohabiting, and married couples. J Fam Violence 1989; 4: 161-80.

[47] Stets JE, Henderson DA. Contextual factors surrounding conflict resolution while dating: Results from a national study. Fam Relat. 1991; 40: 29-36.

[48] White JW, Koss MP. Courtship violence: Incidence in a national sample of higher education students. Violence Vict 1991; 6: 24756.

This is an open access article licensed under the terms of the Creative Commons Attribution Non-Commercial License (http://creativecommons.org/licenses/bync/3.0/), which permits unrestricted, non-commercial use, distribution and reproduction in any medium, provided the work is properly cited. 